\title{
Electrical Events in Specialized Muscle Fibers of a Mammalian Right Atrium
}

\author{
Part II. A-V Node
}

Atsuyoshi MIYAUCHI, M. D.

Transmembrane potentials and the process of excitation propagation of the rabbit's and canine heart in the A-V node and its vicinity were studied by means of the microelectrode method.

In the vicinity of the $A-V$ node, no action potential showing the slow diastolic depolarization was obtained.

It was inferred that the right and septal branches of the crista terminalis extended into the atrial tissue near the vicinity of the A$V$ node, and it was recognized that the excitation which was conducted most rapidly through both branches of the crista terminalis arrived in the vicinity of the $\mathrm{A}-\mathrm{V}$ node almost at the same tim:.

The configuration of the transmembrane potential of the A-V node was peculiar as compared with the configurations of other tissue of the right atrium excepting the S-A node.

The transmembrane potential recorded from the tissue in the A-V node adjacent to the S-A node was characterized by a slow diastolic depolarization, a low resting potential, a very gentle upstroke of the depolarization phase and a lack of overshoot and plateau.

There was a gradual transition in the configuration of the transmembrane potential that was recorded from a series of points, from the tissue in the A-V node adjacent to the S-A node, to the tissue close to the His bundle.

When the penetration approached the tissue close to the His bundle, the action potential began to show a plateau and a rather rapid upstroke in the depolarization phase. A marked delay was observed in the area between the atrial ordinal muscle lying very close to the $A-V$ node and the tissue in the $A-V$ node adjacent to the $\mathrm{S}-\mathrm{A}$ node. The conduction rate in this tissue was $0.03 \sim 0.025$ M. $/ \mathrm{sec}$.

$I^{\mathrm{T}}$ $T$ has been well known that there occurs a considerable delay in the transmission of the stimulus from the atrium to the ventricle through the $A-V$ node.

From the First Department of Internal Medicine, School of Medicine (Director: Prof. S. HIBINO, M. D.), and the Research Institute of Environmental Medicine (Director: Prof. H. TOYOSHIMA, M. D.), Nagoya University, Nagoya, Japan. 
In 1910, Hering ${ }^{1)}$ indicated that in the mammalian heart most of the delay occurred in the atrial portion of the specialized structure described by Tawara ${ }^{2)}$ as the atrioventricular node. Thereafter, many efforts have been made to ascertain the details of the propagation of excitation in the A-V node region. Scher et al., ${ }^{3)}$ Durrer et al.,4) and Pruitt ${ }^{5)}$ recorded intranodal electrical events through the use of plunge electrodes. Recently, the advent of the microelectrode has made it possible to provide a precise demonstration of the electrical events in the cardiac muscle cells.

According to Hoffman et al., ${ }^{6)}$ the slow conduction of the impulse in the A-V node near the atrial border is responsible for a major part of the delay in the transmission of the stimulus from the atrium to the ventricle through the $A-V$ node.

Horibe, ${ }^{7)}$ one of the author's colleagues, employing a microelectrode, demonstrated that the stimulus from the S-A node was conducted most rapidly to the $\mathrm{A}-\mathrm{V}$ node region along the right and septal branches of the crista terminalis. However, the details of the transmission of the stimulus in the $A-V$ node and its vicinity still remained obscure. In the present paper, the propagation of the excitation in the $A-V$ node region was studied by means of the microelectrode method.

\section{Method}

Eight healthy adult mongrel dogs weighing $5 \sim 10 \mathrm{Kg}$. and 12 healthy adult rabbits weighing $2 \sim 2.9 \mathrm{Kg}$. were used for the experiments described in this paper. They were anaesthetized by the intraperitoneal administration of $100 \mathrm{mg}$. of methylhexabital natrium per $\mathrm{Kg}$. of body weight.

After the anaesthesia, the chest was opened and the heart was removed as quickly as possible into a receptacle filled with oxygenated Tyrode's solution which was kept at a constant temperature level of $32 \sim 34^{\circ} \mathrm{C}$. A large specimen of the both atria was prepared by separating from both ventricles along a line about $0.5 \mathrm{~cm}$. below the atrioventricular ring. The left atrium was separated from right atrium slightly to the left of the atrial septum. Then the right atrium was opened by making a small cut through the atrial free wall along the anterior part of the atrial septum. The specimen was spread out and pinned on a paraffin block in such a manner that the endocardial surface faced out away from the paraffine block, and then the paraffine block along with the entire preperation was immersed in a small thermostatic bath. Penetrations were made from the endocardial surface of the specimen.

The bath was constantly irrigated with isothermic Tyrode's solution oxygenated with bubbling saturated oxygen. The experiments were performed under the condition of a spontaneous regular sinus rhythm and that of artificial driving.

During artificial driving, the heart was stimulated at a constant frequency of about 100 cycles per minute through the use of bipolar electrodes placed on 


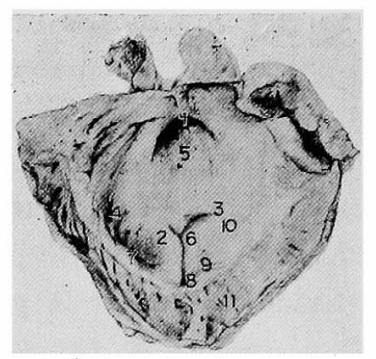

Fig. 1. Endocardial surface of the right atrium. 1: S-A node 2: right branch of the crista terminalis 3 : septal branch of the crista terminalis 4: $\mathrm{Mm}$. pectinati 5: superior vena cava 6 : inferior vena cava $7: \mathrm{A}-\mathrm{V}$ fibrous ring 8 : orifice of the coronary sinus 9: A-V node 10: interatrial septum 11: interventricular septum.

the S-A node region. The intensity of the stimulus was $3 \sim 4$ volts for a duration of 2 milliseconds. Whenever arrhythmia occurred, the experiment was discontinued.

As a time reference, the surface electrogram wàs recorded from the S-A or A-V nodal region through the use of an unipolar electrode or with contiguous bipolar electrodes.

The composition of the Tyrode's solution, the technique of irrigation, the apparatus and the technique for transmembrane potential recording by means of a microelectrode were the same as previously reported.

Artefactual movement of the electrode disturbs the tracing of the transmembrane potential on the electrogram with relation to the time reference, therefore, it is necessary that the electrode be always kept free from any incidental movement. Thus, the measurement of the distance between each penetrated point becomes impossible when the tip of the electrode is artefactually moved by touching it or by some other accident.

\section{RESULT}

1) The transmembrane action potentials recorded from the vicinity of the $\mathrm{A}-\mathrm{V}$ node were observed to display 3 different type of tracings.

One type is characterized by the small amplitude in its membrane resting potential, its steep depolarization upstroke, a lack of overshoot, and the lack of a plateau in the repolarization phase. This type was nearly identical with the tracing of the transmembrane potential obtained from the atrial free wall. This type was referred to as Type I (Fig. 2-a, b).

Another type was characterized by a large amplitude in its membrane 


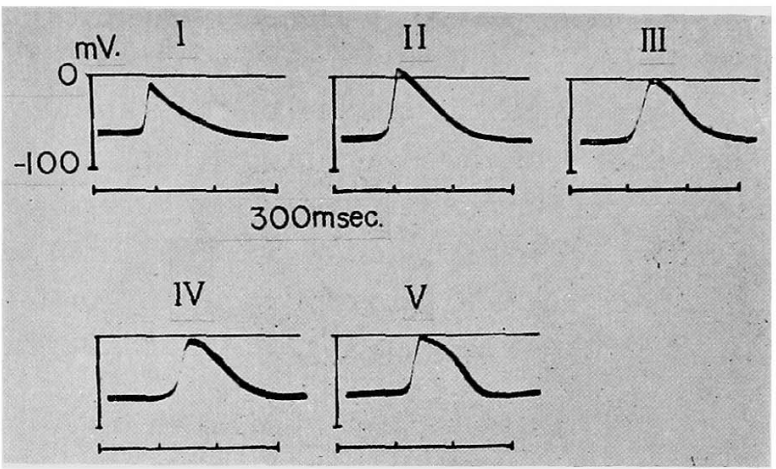

Fig. 2-a. The schema or the configuration of the action potential in the rabbit's heart recorded from the A-V node and its vicinity.

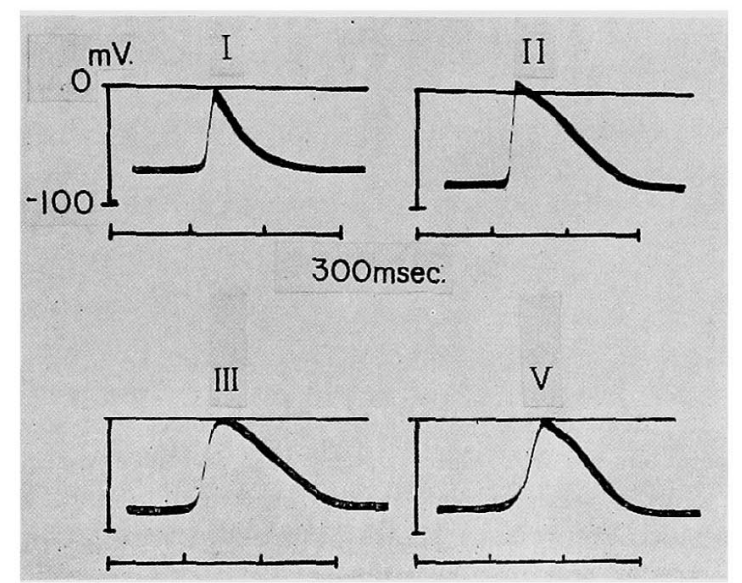

Fig. 2-b. The schema of the configuration of the action potential in the canine heart recorded from the $A-V$ node and its vicinity. The above were recorded at the velocity of $10 \mathrm{~cm}$. $/ \mathrm{sec}$. Since 2 widths of $f 1 \mathrm{~m}, 35 \mathrm{~mm}$, and $80 \mathrm{~mm}$, were used, the calibrations varied; therefore, in order to unify the results, all features were recorded schematically.

resting potential, its steep depolarization upstroke, a sharp peaked overshoot, and a short plateau in the repolarization phase. The plateau was not so noticeable as those seen in the membrane action potentials from the ventricular muscle fibers. This type was referred to as Type II (Fig. 2-a, b).

Type II was almost identical with the tracing of the transmembrane potential obtained from the crista terminalis. The last type was characterized by a small amplitude in its membrane resting potential, its gentle depolarization upstroke, a lack of overshoot, and by a short plateau in the 
repolarization phase. The plateau was nearly identical in duration and slope with that of Type II. This type was referred to as Type III. This type was nearly identical with the tracing of the transmembrane potential obtained from the vicinity of the $\mathrm{A}-\mathrm{V}$ fibrous ring.

A slow diastolic depolarization was not observed in any of these 3 types. Tracings of the membrane action potential from a series of points along a line vertical to the A-V fibrous ring at the posterior edge of the coronary sinus, were demonstrated in Fig. 3. The interval between each

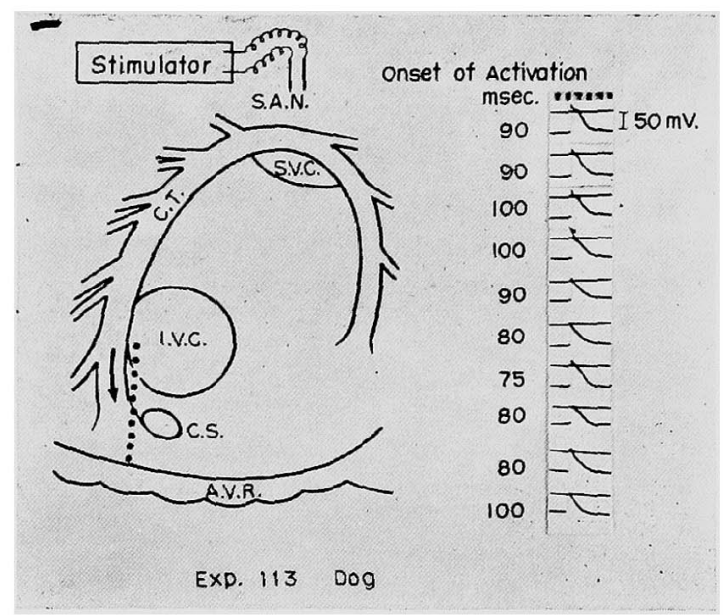

Fig. 3. Electric driving of the canine heart was accomplished from a point on the S-A node. Near the posterior margin of the coronary sinus, a series of penetrations were made along a line vertical to the A-V fibrous ring. The diagram shows each lead point, and the configuration and activation time of the action potential recorded from each of these points (see the text).

point penetrated was $1 \mathrm{~mm}$. The data were obtained under the condition of artificial driving from a point on the S-A nodal region of a canine heart.

The tracing of the membrane action potential obtained from the point nearest to the A-V fibrous ring was that of Type III. The tracings of the membrane action potential from the remaining 9 points were those of Type II. Type I could not be recorded from any of these points. Activation time is given in milliseconds. Among these series of points, the point nearest to the edge of the coronary sinus was earliest in its onset of activation and was 75 msec.

Intracellular records from a series of points, at intervals of $0.5 \mathrm{~mm}$., along a line vertical to the A-V fibrous ring at the anterior edge of the inferior vena cava were demonstrated in Fig. 4. The tracings were obtain- 


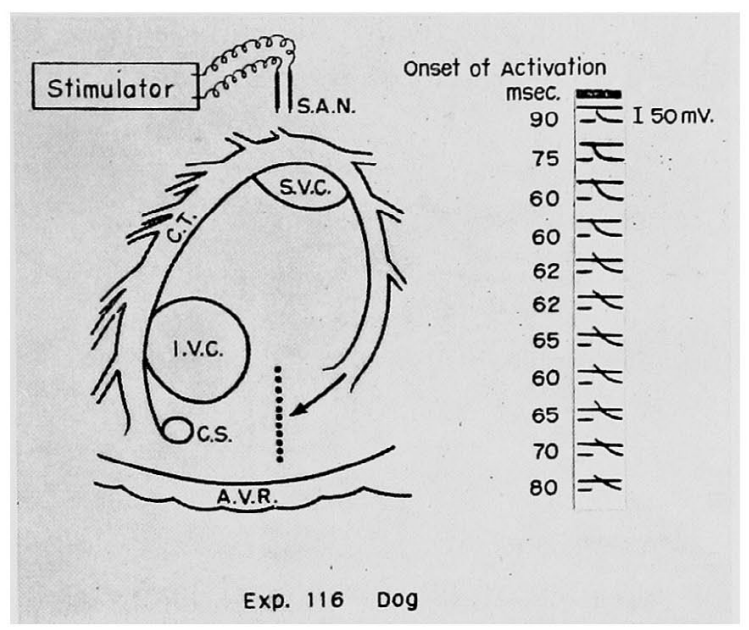

Fig. 4. Electric driving of the canine heart was accomplished from a point on the S-A node. Near the anterior margin of the orifice of the inferior vena cava, a series of penetrations were made along a line vertical to the A-V fibrous ring. The diagram shows each lead point, and the configuration and activation time of the action potential recorded from each of these points (see the text).

ed under the condition of artificial driving from a point on the S-A nodal region of canine heart.

Among these tracings, the upper 2 were those of Type I, the following 7 were those of Type II, and the remaining 2 were those of Type III. The activation times of the 7 points, from where the Type II action potential was recorded, were between 60 to $65 \mathrm{msec}$. Those of the 2 points from where the Type I action potential was recorded, were 90 and 75 msec. respectively, and those of the remaining 2 points from where the Type III action potential was recorded, were 70 and $80 \mathrm{msec}$. respectively. From these findings, it was supposed that the area including the 7 points exhibiting Type II tracings depolarizes earlier than the areas containing the 4 other points.

Next, in order to ascertain the transmission of stimulus in the entire area in the vicinity of the $\mathrm{A}-\mathrm{V}$ nodal region, the intracellular records under a spontaneous sinus rhythm were obtained from the vicinity of the canine atrioventricular region (Fig. 5). As a time reference, an unipolar lead electrogram was simultaneously recorded from the point marked by a large dot in Fig. 5.

Units inserted at the left lower tracings A-1, 2, 3 and to the left on the right side of tracings $\mathrm{B}-1,2,3,4,5,6, \mathrm{C}-1,2$, and $\mathrm{D}$ of the transmembrane action potentials show the activation times in milliseconds while those inserted at the right lower tracings $A 1,2,3$ and to the right on the 


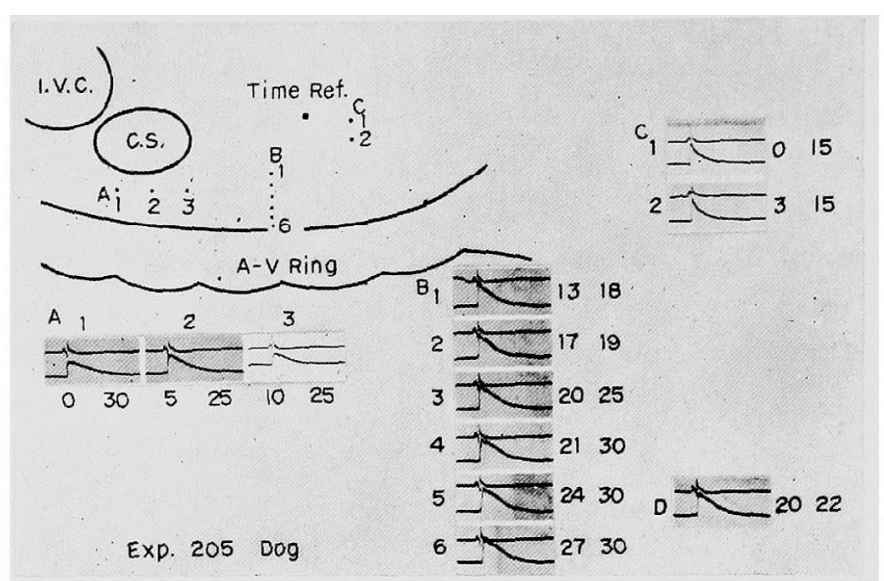

Fig. 5. The configuration of the action potential, the activation time (left side) and the duration of the rising phase (right side) in the vicinity of the canine $A-V$ node.

right side of tracings $\mathrm{B} 1,2,3,4,5,6, \mathrm{C} 1,2$, and $\mathrm{D}$ of the transmembrane action potentials show the duration of the rising phase in milliseconds.

Points 1, 2 and 3 in the A group are points along a line selected in a narrow area between the orifice of the coronary sinus and the A-V ring. The action potentials from these 3 points were those of Type III. The unusually low amplitude of the membrane resting potential was thought to be due to a technical failure during the process of penetration. The reason for this technical failure is not as yet certain; however, it was difficult to obtain a deep resting level from this area.

Points 1 through 6 in the $B$ group are a series of points, at intervals of $1 \mathrm{~mm}$., along a line vertical to the A-V fibrous ring and $4 \mathrm{~mm}$. distant from a line representing the anterior edge of the coronary sinus.

Point 1 in the $B$ group exhibited a Type I tracing while points 2 and 3 exhibited a Type II tracing. Points 4, 5 and 6, which are in the vicinity of the A-V fibrous ring, exhibited a Type III tracing.

Points 1 and 2 in the $C$ group were located near the atrial septum. The action potential from these points exhibited a Type I tracing.

Point $\mathrm{D}$ was located near the $\mathrm{A}-\mathrm{V}$ fibrous ring and was $8 \mathrm{~mm}$. away from the anterior edge of the coronary sinus. The membrane action potential from this point displayed a Type III tracing. The activation time of point 1 in the A group was almost the same as that of point 1 in the G group.

2) Atrioventricular node.

The author tried to obtain an intracellular record from the canine and rabbit's atrioventricular node.

The transmembrane action potential from the $A-V$ node was also 
characterized by a slow diastolic depolarization prior to the onset of the membrane action potential similar to that seen in the S-A node and other cell groups having automaticity.

The transmembrane action potentials from the A-V node of the rabbit's heart could be divided into 2 types as illustrated in Fig. 2-a. (Types IV and V).

Type IV was characterized by a gently sloped slow diastolic depolarization, a low membrane resting potential, a very gentle depolarization upstroke, and a short plateau. In a few cases there was a notch in the depolarization upstroke.

Type $\mathrm{V}$ was characterized by a gently sloped slow diastolic depolarization, a gentle depolarization upstroke, and a clear plateau. The plateau was clear but not so long lasting as that seen in the membrane action potential of the ventricular muscle fibers and was nearly the same as that of the Purkinje fibers.

Intracellular records from a series of points at intervals of $0.5 \mathrm{~mm}$. in the region of the A-V node along the anterior margin of the coronary sinus was demonstrated in Fig. 6. These points are about $2 \mathrm{~mm}$. away from the anterior margin of the coronary sinus.

The experiment was performed under the condition of a spontaneous sinus rhythm. As the time reference, the contiguous bipolar lead electrogram was recorded from a point on the surface of the S-A node region.

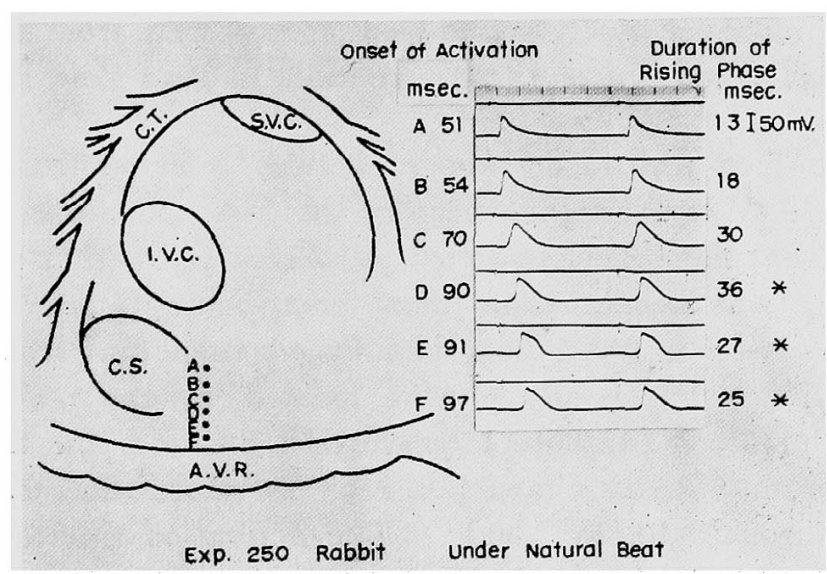

Fig. 6 The configuration, the activation time (left side) and the duration of the rising phase (right side) of the action potential recorded from the A-V node and the atrial ordinal muscleadjacent to the node in the rabbit's heart. In the records marked with a star, the slow diastolic depolarization could be observed. The experiment was performed under a spontaneous sinus beat. As the time reference, a bipolar lead ëlectrogram was introduced from a point on the S-A node. 
Units shown on the left of the transmembrane action potential tracings give the activation time in msec., while those shown on the right of the same tracings give the duration of the rising phase in milliseconds.

The star designates that the action potential has a slow diastolic depolarization.

The action potential from points $A, B$ and $C$ exhibited no slow diastolic depolarization and belonged to the Type I, II and III tracings respectively. The action potential from points $\mathrm{D}, \mathrm{E}$ and $\mathrm{F}$ exhibited a slow diastolic depolarization. Among them, the action potential from point $\mathrm{D}$ belonged to the Type IV tracing, while those from points $E$ and $F$, to the Type $\mathrm{V}$ tracing.

There was a marked shift in the configuration of the action potential from point $A$ to point $E$, even though the distance between points $A$ and E only was $2.0 \mathrm{~mm}$.

The duration of the rising phase of the action potential recorded from point $D$ was $36 \mathrm{msec}$. and was the longest. Those from points $E$ and $F$ were 27 and $25 \mathrm{msec}$. respectively.

The configuration of the action potential recorded from points $D, E$ and $F$ was quite similar to that recorded from the A-V node as reported by Hoffman et al. ${ }^{\text {) }}$

The action potentials recorded from points $A$ and $B$ were nearly the same as those of the atrial muscle fibers. The action potential recorded from point $\mathrm{C}$ was nearly the same as that obtained from the vicinity of the A-V fibrous ring. All of these potentials had no slow diastolic depolarization.

From the fact mentioned above, it was inferred that point $D$ was located in the A-V nodal region near to the S-A node. On the contrary, from the fact that the depolarization upstroke of the action potential from points $E$ and $F$ was steeper than that from point $D$, and the plateau from these points was more clear and longer than that from point $D$, it was inferred that points $E$ and $F$ were located in an $A-V$ nodal region near the His bunble. The author measured time from the time reference to the onset of activation of each point to ascertain the transmission of the stimulus through the $\mathrm{A}-\mathrm{V}$ node. The activation time of points $\mathrm{A}, \mathrm{B}$, $\mathrm{C}, \mathrm{D}, \mathrm{E}$ and $\mathrm{F}$ was $51,54,70,90,91$ and $97 \mathrm{msec}$. respectively. A marked delay was observed at points $C$ and $D$. In the $A-V$ nodal region the conduction rate was observed to be generally low and between points $C$ and $\mathrm{D}$, it was especially low being about $2.5 \mathrm{~cm}$. per second. With the canine heart, it was very difficult to obtain an intracellular record from the A-V nodal region; however, it was successfully obtained from several hearts. The action potential from the A-V node of the canine heart was 


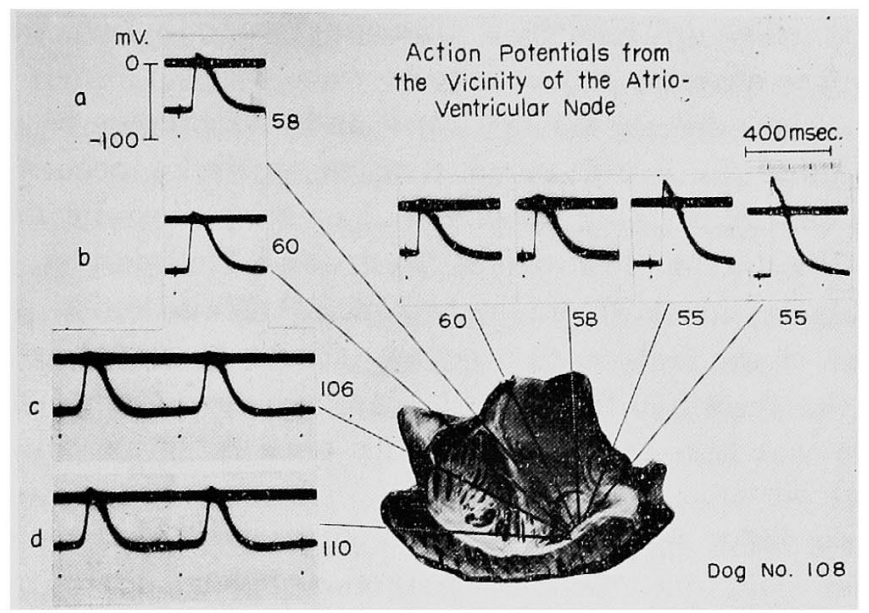

Fig. 7 The configuration and the activation time of the action potential recorded from the $\mathrm{A}-\mathrm{V}$ node and its vicinity in the cannine heart.

also characterized by a slow diastolic depolarization. Fig. 7 reproduces the transmembrane action potential from the canine A-V nodal region. The records on the left side of Fig. 7 were obtained from a series of points along the anterior edge of the coronary sinus. Point $d$ was about $3 \mathrm{~mm}$. away from the anterior edge of the coronary sinus. The intervals between $a-b, b-c$ and c-d were $1 \mathrm{~mm} ., 2 \mathrm{~mm}$. and $1 \mathrm{~mm}$. respectively.

The action potential obtained from points a and $b$ was a Type II tracing; however, that obtained from $\mathrm{c}$ and $\mathrm{d}$ was a Type $\mathrm{V}$ tracing and it exhibited a slow distolic depolarization.

The activation time at points $\mathrm{a}, \mathrm{b}, \mathrm{c}$ and $\mathrm{d}$ was 58, 60, 106 and 110 msec. respectively. A marked delay was observed at point c. Tracings from points $b$ and $c$ were absent due to a technical failure during the process of penetration.

In these experiments, the membrane action potential of a Type IV tracing could not be recorded probably because the tracings from points $b$ and $\mathrm{c}$ could not be obtained due to faulty penetration. Had tracings from these points been obtained, the membrane action potential of a Type IV tracing might have been observed.

\section{Discussion}

It has already been known that specialized muscle fiber has automaticity (Lewis, ${ }^{8)}$ Mönckeberg, ${ }^{9)}$ Goldenberg and Rothberger, ${ }^{10)}$ and Bozler ${ }^{11)}$ ). Recently it was also found by Wcidmann, ${ }^{13}$ ) Trautwein, ${ }^{14)}$ West, ${ }^{15)}$ and Hoffman et al. ${ }^{6)}$ that the slow potential change appears preceding the 
rapid depolarization upstroke in a transmembrane action potential from the tissue having automaticity.

The potential change is very slow and it increases in its amplitude progressively until the rapid depolarization upstroke occurs. Therefore, this potential change is called prepotential or slow diastolic depolarization. According to Weidmann, Trautwein, West, and Hoffman et al., the slow diastolic depolarization is found in a transmembrane action potential from a muscle fiber of the $\mathrm{S}-\mathrm{A}$ nodal region, the $\mathrm{A}-\mathrm{V}$ nodal region, the $\mathrm{His}$ bundle, and the Purkinje fibers. The appearance of this slow diastolic depolarization was also confirmed by the authors on a muscle fiber in the S-A nodal region.

From these facts, it may be possible to suppose that the muscle fibers exhibiting the slow diastolic depolarization belong to the so-called specialized muscle fibers.

Within the limitations imposed through the use of the microelectrode method, the fact that the tracing, produced by an ordinal muscle fiber of the right atrium, of a transmembrane action potential from the muscle fibers surrounding the $\mathrm{A}-\mathrm{V}$ node did not exhibit the slow diastolic depolarization, appears to suggest that there is no specialized muscle fiber in the muscle fibers surrounding the $A-V$ node.

According to Hoffman et al., ${ }^{12)}$ however, a transmembrane action potential recorded from a Purkinje fiber of the cat's or canine heart sometimes fails to show the slow diastolic depolarization; therefore, it may be probable that depending upon their condition, the specialized muscle fibers sometimes fail to exhibit the slow diastolic depolarization.

In the present experiment, the cell layers penetrated were limited to the superficial myocardial layers underlying the endocardium for in a deep zone, penetration was impossible. The author, therefore, may be incorrect in assuming the absence of specialized muscle fiber simply because the experimental results showed no slow diastolic depolarization in the transmembrane action potential of the muscle fibers surrounding the $\mathrm{A}-\mathrm{V}$ node.

According to a histological study by Holmes, ${ }^{16)}$ and $\overline{\text { Osawa }}{ }^{17}{ }^{17}$ specialized muscle fiber was described to exist between the S-A and A-V nodes.

Why the author could not find any action potential tracing characterized by the slow diastolic depolarization is not as yet certain. Perhaps this was due to superficial penetrations or inadequate intervals of exprolation. On the other hand, the muscle fibers surrounding the A-V node might bear no characteristics of the specialized muscle fiber.

There are very few papers relating to the study of the spread of right atrial activation by means of the intracellular electrode. Hoffman 
et al. ${ }^{18)}$ performed some experiments with the intracellular electrode on the rabbit's atrium, and Horibe ${ }^{7)}$ used it on the rabbit's and canine heart.

According to Hoffman et al., ${ }^{18)}$ excitation originating in the S-A node is conducted at the greatest speed in the direction of the A-V node through the S-A ring bundle which lies along the inside of the right and septal branches of the crista terminalis.

Although $\mathrm{Horibe}^{7)}$ failed to observe the S-A ring bundle, he stated that the excitation of the S-A node was conducted most rapidly in the direction of the A-V node through the right and septal branches of the crista terminalis.

A precise description of the microelectrode method in the exploration of the atrial tissue in the vicinity of the A-V node still remains obscure.

The muscle bundle of the crista terminalis gradually decreases in its thickness as it approaches the $\mathrm{A}-\mathrm{V}$ node, and in the vicinity of the $\mathrm{A}-\mathrm{V}$ node, the endocardial surface forms a flat plane, especially in the area from the interatrial septum to the anterior margin of the coronary sinus. It is difficult to differentiate the muscle fibers of the crista terminalis from those of the ordinary atrial muscle fibers. However, the fact that a Type II tracing which is nearly the same as the tracing exhibited by the crista terminalis, was recorded from several points along the peripheral region of the crista terminalis, and that these points were depolarized earlier than the others, seems to support the supposition that the muscle fibers of the crista terminalis may branch out into the vicinity of the A-V node. At the posterior margin of the coronary sinus near the A-V fibrous ring, the muscle bundle of the crista terminalis also progressively loses its characteristic rise as it approaches the $\mathrm{A}-\mathrm{V}$ fibrous ring and in that area it is difficult to differentiate the muscle fibers of the crista terminalis from those of the ordinary atrial muscle fibers.

However, as may be seen in Fig. 3, at every point except the point nearest to the $\mathrm{A}-\mathrm{V}$ fibrous ring, the tracing of the transmembrane action potential was that of Type II. The point located nearest to the coronary sinus in this series began to depolarize earlier than that of any of the other points. From these facts, it may be inferred that the muscle bundle of the crista terminalis extended into the region where the Type II tracing was recorded, and through this bundle, the excitation arrives at this region earlier than in the other regions.

In the author's experiments, the S-A ring bundle that Hoffman et al. ${ }^{18)}$ considered as the bundle through which excitation is conducted most rapidly was not observed in the vicinity of the $A-V$ node; however, the author's results were in agreement with Horibe'si) report which pointed out that the excitation of the S-A node was conducted most rapidly in the direction of the A-V node through the both branches of the crista 
terminalis.

Now, the important question is what activates the A-V node, the excitation which has propagated rapidly through the crista terminalis or the excitation which has propagated later than that of the crista terminalis through the so-called specialized muscle fiber or some other routes. In order to study this problem, the author performed experiments on 4 dogs and 10 rabbits in which the right and septal branches of the crista terminalis were severed. In this experiment, the intracellular electrogram was introduced from the $\mathrm{A}-\mathrm{V}$ node, and as a time reference a bipolar contiguous lead electrogram was recorded simultaneously from a point on the S-A node. Then the right and septal branches of the crista terminalis were cut off, or heated respectively. In this experiment, there were many technical difficulties e.g., to keep an electrode free from artefactual movement or dislocation.

Inspite of these technical difficulties, it was demonstrated that when the right branch was cut off, the activation time of the $A-V$ node was delayed for approximately $20 \mathrm{msec}$. Further when the septal branch was severed, an additional delay of about 20 msec. was noted. When the specithens were heated, a conduction block occurred between the S-A and A$\mathrm{V}$ nodes. In these experiments, it seemed that some factor was produced which strongly suppressed the excitation process of the right atrium, and and it still remains a question as to whether the excitation through the crista terminalis or the excitation from some other route acts effectively on $\mathrm{A}-\mathrm{V}$ node.

When the right atrium begins to contract, the crista terminalis should begin its contraction early and rapidly in order to prevent the blood from flowing backward from the right atrium to the superior and inferior venae cavae. For that purpose, it would seem effective to propagate the excitation rapidly through the crista terminalis.

Further, in order to send the blood from the right atrium into the right ventricle it is supposed that the right atrial free wall begins its contraction rapidly. For that purpose, it would seem effective to propagate the excitation from the crista terminalis rapidly through $\mathrm{Mm}$. pectinati in the direction of the $\mathrm{A}-\mathrm{V}$ fibrous ring.

On the other hand, after enough blood from the right atrium has entered the right ventricle, the right ventricle then sends it to the pulmonary artery; therefore, a delay should occur in some part of the excitation process between the right atrium and right ventricle.

It is supposed that the $\mathrm{A}-\mathrm{V}$ node exists in order to produce a delay between the right atrium and right ventricle for the purpose mentioned above.

If this be true, the $\mathrm{A}-\mathrm{V}$ node has no need for early excitation through 
the crista terminalis. Consequently, it is supposed that the rapid propagation of the excitation to the A-V node through the crista terminalis occurs, not for the purpose of activating the A-V node carly, but for the purpose of activating both caval orifices in their early stage of contraction.

In the present experiments, sufficient results to support this supposition were not obtained; however, further studies must be conducted on which route the excitation is transmitted to activate the $A-V$ node effectively.

It has already been reported by Matsuda et al., ${ }^{19)}$ Sano et al., ${ }^{20)}$ Hoffman et al. $^{6)}$ and Paes de Carvalho et al. ${ }^{21)}$ that the configuration of the membrane action potential recorded from the A-V node was very peculiar.

According to Matsuda et al. ${ }^{18)}$ the characteristics of the cellular action potential recorded from the A-V nodal region are as follows: 1) the slow rise of depolarization, 2) the definite delay in the spike from the start of the depolarization amounting to from 40 to $80 \mathrm{msec}$, preceding the spike there is a slow rise simulating the synaptic potential, at times a step-like potential, 3) the overshoot is small or absent, 4) the slight undershooting following the repolarization and the slightly lowered resting potential.

According to Hoffman et al., ${ }^{6)}$ the features of the action potential recorded from the atrial portion of the rabbit's $A-V$ node are as follows: The rising velocity is low, the amplitude of the reversal is decreased and the peak is rounded, some slow diastolic depolarization is present and the maximum diastolic potential is low, there is a prominent foot on the rising phase of the action potential. Records obtained at several sites between the atrial portion of the node and the His bundle show a gradual transition in the action potential shape.

The Type IV tracing (Fig. 2), which the author obtained from almost all the rabbit's hearts, showed the slow diastolic depolarization and was more agreeable in form to the action potential tracing which Hoffman et al. had recorded from a point on the atrial portion of the A-V node rather than to the tracing recorded by Matsuda et al. from the A-V nodal region.

The action potential of point D in Fig. 6 exhibits a Type IV tracing, and this potential was recorded from the point in the canine $A-V$ node which was observed to be nearest to the S-A node. This region is considered to be identical with the atrial portion of the A-V node indicated by Hoffman.

The Type $\mathrm{V}$ tracing also showed the slow diastolic depolarization, and this trace could be obtained from almost all the rabbits' and a few dogs' hearts.

This Type was recorded from the part nearer to the His bundle than the part from which Type IV was recorded. Its plateau was clear and 
the rising phase was steeper than that of Thye IV; therefore, it was considered to be a transitional shifting Type IV to the action potential of the His bundle. These results were in close agreement with the results of Hoffman et al. ${ }^{\text {? }}$.

In regard to the delay of the activation time in the A-V node, Hoffman et al. ${ }^{b}$ ) recognized that the decremental conduction occurred at the atrial portion of the $A-V$ node.

According to Paes de Carvalho et al., ${ }^{21)}$ histologically the $\mathrm{A}-\mathrm{V}$ node consisted of an A-V layer, an $\mathrm{N}$ layer and an $\mathrm{N}-\mathrm{H}$ layer and the decremental conduction occurred in the A-N layer nearest to the $\mathrm{N}$ layer, and in the $\mathrm{N}$ layer.

On the other hand, according to Matsuda et al., ${ }^{19}$ although the start of the depolarization of the $A-V$ node is almost simultaneous with that of the adjacent atrial ordinary muscle fiber, the spike is delayed very noticeably. They considered the $\mathrm{A}-\mathrm{V}$ conduction delay would be due to the spike delay of the action potential which occurred in the course of the impulse conduction in a short distance at the proximal portion of the A-V node, owingto the characteristic behavior of the cellular membrane in this portion.

From the results of the author's experiments, as seen in Fig. 6, it was recognized that the excitation propagated slowly between the points $B$ and C which were supposed to exist in the adjacent atrial ordinary muscle and point $D$ which was supposed to be in the $A-V$ node most closely adjacent to the S-A node. This fact is in close agreement with the results of Ho.man et al. ${ }^{6)}$ The author's results concerning the slow rate of depolarization nearly coincided with those of Matsuda et al. ${ }^{19)}$ However, with regard to the time of the onset of depolarization, there was a considerable difference between the $\mathrm{A}-\mathrm{V}$ node and the adjacent atrial ordinary muscle, thus the author cannot agree with the findings of Matsuda et al.

As the author conducted no histological study, it was difficult to compare the region where the author had observed delay in the activation time, with the A-N layer and $N$ layer where Paes de Carvalho et al. had observed decremental conduction. However, the author's results are not contradictory to their results concerning the portion in which the delay was observed.

According to Hoffman et al. ${ }^{6)}$ the conduction rate of the $A-V$ node was $0.05 \sim 0.02 \mathrm{M}$. $/ \mathrm{sec}$, at the part near the junction of the atrium with the $\mathrm{A}-\mathrm{V}$ node; in the author's experiments, it was $0.03 \sim 0.025 \mathrm{M}$. $/ \mathrm{sec}$. in the A-V node at the part most closely adjacent to the S-A node; thus, the author's result coincided with that of Hoffman et al.

In Fig. 6, the configuration of the action potential recorded from point $C$ was nearly the same as that in the vicinity of the A-V fibrous ring.

There is a tendency for the conduction velocity to become slower as the excitation approaches the A-V node. 
This fact is almost similar to the result of Horiba's ${ }^{22)}$ study concerning the excitation process in the vicinity of the $\mathrm{A}-\mathrm{V}$ fibrous ring.

The propagation of the excitation required the longest time from point $C$ in the vicinity of the $A-V$ node to point $D$ in the $A-V$ node.

In these experiments, since it was impossible to explore the entire area where the $\mathrm{A}-\mathrm{V}$ node was supposed to exist, no exact conclusion could be reached, however, the following supposition could be considered from these experiments. As Horibe ${ }^{7)}$ already reported, the A-V fibrous ring lying between the atria and ventricles has some built-in mechanism which prevents the immediate propagation of the excitation from the atria to the ventricles. Also in the vicinity of the A-V node, the Type III tracing was obtained and this tracing was nearly identical to that found in the vicinity of the A-V fibrous ring, moreover, the velocity of the excitation became slower, thus, it may be supposed that there is nearly the same built-in mechanism in this area which prevents the immediate propagation of the excitation as that found in the vicinity of the $A-V$ fibrous ring.

That is, as the excitation approaches the A-V node, it assumes the process of propagation similar to that in the vicinity of the A-V fibrous ring and the velocity of the excitation becomes slow. From this, it may be suggested that there is possibly some particular entrance through which the excitation of the atria is propagated into the $A-V$ node, in the same manner as the excitation is propagated from the right atrium to the ventricle through the $A-V$ node.

Of course, it may be supposed that there are many other factors which cause delay in conduction propagation. For example, according to Hoffman et al., ${ }^{6)}$ decremental conduction could arise from any of the several changes in the fiber properties, i. e., fiber diameter, threshold, membrane capacitance or resistance, or low resting potential; however, to date there is no secure data concerning these factors and further studies in the future regarding these problems are warranted.

\section{Summary}

Transmembrane potentials and the process of excitation propagation of the rabbit's and canine heart in the $\mathrm{A}-\mathrm{V}$ node and its vicinity were studied by means of the microelectrode method.

(1) In the vicinity of the $\mathrm{A}-\mathrm{V}$ node, no action potential showing the slow diastolic depolarization was obtained.

The configuration of the action potential recorded from this area exhibited a tracing similar to that of the action potential recorded from the atrial ordinary muscle. 
(2) It was inferred that the right and septal branches of the crista terminalis extended into the atrial tissue near the vicinity of the A-V node. In these areas the arrival times of the excitation through both branches of the crista terminalis were almost the same.

(3) It was impossible to clarify whether the excitation through the crista terminalis activated the $A-V$ node or whether it was activated by the excitation through some specialized muscle, in which the conduction rate was slower than that of the crista terminalis.

(4) The configuration of the transmembrane potential of the A-V node was peculiar.

The transmembrane potential recorded from the atrial tissue in the A-V node adjacent to the S-A node was characterized by a slow diastolic depolarization, a low resting potential, a very gentle upstroke of the depolarization phase and a lack of overshoot and plateau.

When the penetration approached the tissue close to the His bundle, the action potential began to show a plateau and a rather rapid upstroke of the depolarization phase.

(5) A marked delay was observed in the area between the atrial ordinary muscle close to the $A-V$ node and the tissue in the $A-V$ node adjacent to the S-A node.

The conduction rate in this area was $0.03 \sim 0.025 \mathrm{M} . / \mathrm{sec}$.

\section{AGKNOWLedGement}

The author wishes to acknowledge the generous advice and instruction which were offered by Prof. Susumu Hibino, Prof. Hideo Toyoshima and Assist. Prof. Kazuo Yamada.

The author is grateful to Dr. Y. Mizuno, Dr. T. Nagaya and Dr. S. Yasui. Many thanks are also expressed to Dr. M. Horiba and Dr. H. Horibe. An outline of the present paper was published by speech at the 25th Congress of Japanese Circulation Society in 1961.

\section{REFERENCES}

1. Hering, H. E. : Pflüger's Arch. ges, Physiol. 131 : 572, 1910

2. Tawara, S. "Das Reizleitungssystem des Saugetierherzens", Gustav Fischer Jena, 1906.

3. Scher, A. M., Rodriguez, M. I., Lhkane, J., and Young, A. C.: Circulat. Res. 7: 54, 1959.

4. van der Kooi, M. W., Durrer, D., van Dam, R., and van der Tweel, L. H.: Am. Heart J. $51: 684,1956$.

5. Pruitt, R. D. and Essex, H. E. : Circulat. Res. 8: 149, 1960.

6. Hoffman, B. F., Paes de Carvalho, A., Carlos de Mello, W., and Granefield, P.F.: Criculat. Res. 7 : 11, 1959.

7. Horibe, H.: Jap. Circulat. J. 25: 583, 1961. 
8. Lewis, T.: The mechanism and graphic registration of the heart beat. 3rd ed. Show \& Sons, London, 1925.

9. Mönckeberg, J. G.: Der Funktionelle Bau der Saugetierherzens. in Bethe's Handbuch der Normalen und Pathologischen Physiologie, 7 ter Bd., Erste Halfte, Springer, Berlin, 1926.

10. Goldenberg, M. and Rothberger, C. J.: Pflug. Arch. 237: 295, 1936.

11. Bozler, E.: Am. J. Physiol. 138: 273, 1943.

12. Hoffman, B.F. and Cranefield, P. F. : "Electrophysiology of the heart", McGraw-Hill, New York, p. 176, 1960.

13. Weidmann, S.: J. Physiol, 115: 227, 1951.

14. Trautwein, W., Gottstein, U., and Federschmidt, K.: Pflug. Arch. 258 : 243, 1953.

15. West, T. C.: J. Pharmacol. Exp. Therap. 115: 283, 1955.

16. Holmes, A. H.: J. Anat 55: 269, 1921.

17. Ōsawa, M.: Jap. Circulat. J. 23 : 1014, 1959 (In Japanese),

18. Paes de Carvalho, A., de Mello, W. G., and Hoffman, B. F.: Am. J. Physiol, 196 : 483, 1959.

19. Mastuda, K., Hoshi, T., and Kameyama, S.: Töhoku J. Exp. Med. 68 : 8, 1958.

20. Sano, T., Tasaki, M., and Shimamoto, T.: Circulat. Res. 7: 700, 1959.

21. Paes de Carvalho, A. and de Almeida, D. F.: Circulat. Res. 8: 801, 1960.

22. Horiba, M.: Jap. Circulat. J. (In press.) 